\title{
Predicting the Permeability and Tensile Properties of Multilayer Films from the Properties of the Individual Component Layers
}

\author{
Chi-Hsien HuANG, Jiann-Shing Wu, and Chun-Chin HuANG ${ }^{* \dagger}$ \\ Department of Applied Chemistry, National Chiao Tung University, 1001 Ta Hsueh Road, Hsinchu 300, Taiwan, R.O.C. \\ ${ }^{*}$ Department of Mold and Die Engineering, National Kaohsiung University of Applied Science, Kaohsiung 807, Taiwan, R.O.C.
}

(Received October 10, 2003; Accepted February 7, 2004; Published May 15, 2004)

\begin{abstract}
We have fabricated typical three-layer films (A/B/C multilayer structures), comprising polyamide-6 (PA-6), low-density polyethylene (LDPE), and adhesive (low-density ethylene grafted with maleic anhydride, LDPE- $g$ $\mathrm{MAH}$ ), by a coextrusion blown-film process using various compositions of the three layers. With the goal of predicting the permeability and tensile properties of the three-layer films, we examined model predictions and the properties of the individual component layers to provide an economical and efficient pathway to designing desired multilayer structures. We used the series model for predicting permeability; a good agreement exists between experimental data and this model for predicting both gas and water vapor permeabilities of three-layer films having various contents of PA-6. By using the additive rule model, we can also predict the tensile properties, including the true yield stress, strain hardening parameter, and tensile modulus of the three-layer film from those of the individual component layers, with particularly high accuracy in the true stress-strain relationship. [DOI 10.1295/polymj.36.386]

KEY WORDS Coextrusion / Multilayer / Permeability / Plastic Deformation / Strain Hardening / Tensile Property /
\end{abstract}

Coextrusion is a process in which two or more polymers are extruded simultaneously and joined together to form a single structure having different properties in each layer. This process is used to achieve a broad range of properties in the final material that are not available in any of the individual materials alone. Coextrusion has become an attractive and economical method to fabricate, for example, multilayer sheets, blown films, cast films, tubing, and containers. ${ }^{1-4}$ The choice of component materials depends on the required end-use applications. The most important requirements for such films are their permeability properties and mechanical strengths.

Low-density polyethylene (LDPE) and polyamide 6 (PA-6) are two important classes of polymers used in coextrusion that are very popular in the packaging industry. LDPE is employed widely because of its low cost, high barrier properties toward moisture, good optical properties, and ease of processing, ${ }^{5-7}$ but its poor barrier property toward oxygen and many organic solvents limits its applicability. ${ }^{8,9}$ On the other hand, PA is a good barrier resin toward oxygen, aromas, and organic solvents and it has high tensile strength, but is relatively expensive and a poor barrier for water vapor. ${ }^{10-13}$ It is possible to combine these two resins into a single structure by using a coextrusion process to form multilayer sheets, films, or containers possessing a multitude of properties. Because of the chemical dissimilarities between these two resins, however, an ex- trudable adhesive is often incorporated into the structure as a tie layer that holds the two resins together. By combining graft and polymer blending, Tanaka et al. ${ }^{14}$ have successfully developed a new generation of tie layer adhesives that maintain high adhesive strengths after thermoforming and orientation. Bo$\operatorname{tros}^{15}$ studied three-layer films (tie/EVOH/tie) using a coextrusion cast-film process and found that the tie layers bind to $\mathrm{EVOH}$ through covalent and hydrogen bonding. Kamykowski ${ }^{16}$ studied the adhesive properties of five-layer coextruded cast films and found that adhesion generally can be improved upon increasing the overall film thickness or the relative amount of the adhesive. The molecular weight of the grafted resin has a small affect on adhesion. Homopolymer diluents outperform random copolymers with respect to their adhesion properties. Because of the incorporation of the tie layer, the single structure comprises a typical three-layer A/B/C configuration (LDPE/tie/ PA-6) with multiple properties arising from the individual component layers.

Previous reports have described the properties, such as permeability and tensile strength, of monolayer materials, such as LDPE and PA-6. ${ }^{12,17-21}$ With the goal of designing a method for effectively predicting the specific properties of a multilayer structure from the properties of its individual component materials, in this paper we examine the permeabilities, including those toward gas and water vapor, and tensile proper-

${ }^{\dagger}$ To whom correspondence should be addressed (Tel: +886-7-3814526 ext 5418, Fax: +886-7-3835015, E-mail: chhuang.ac87g@nctu.edu.tw, cchuang@cc.kuas.edu.tw). 
ties of three-layer films fabricated by a coextruded blown-film process using the series model ${ }^{22}$ and the additive rule ${ }^{23}$ as predicting methods, respectively. These models are economical and efficient tools for designing multilayer sheets, films, and containers to be prepared by coextrusion processes.

\section{EXPERIMENTAL}

\section{Materials}

Commercial-grade low-density polyethylene [LDPE; 6030 F; M.I. $\left(\mathrm{g} / 10 \mathrm{~min}, 190{ }^{\circ} \mathrm{C}, 2.16 \mathrm{~kg}\right)=$ 0.27 ; density $=0.922 \mathrm{~g} / \mathrm{cm}^{3}$ ] was supplied in pellet form by Formosa Plastic Corp. (Taiwan). The polyamide-6 (PA-6; Novamid 1030; M.I. (g/10 min, $\left.240{ }^{\circ} \mathrm{C}, 2.16 \mathrm{~kg}\right)=5$; density $=1.14 \mathrm{~g} / \mathrm{cm}^{3}$ ) was provided in pellet form by Mitsubishi Engineering-Plastics Corp. (Japan). The adhesive, Modic-AP L502, which was obtained in pellet form from Mitsubishi Chemical Corp. (Japan), is a low-density polyethylene-grafted maleic anhydride [LDPE- $g$-MAH; M.I. $\left(\mathrm{g} / 10 \mathrm{~min}, 190^{\circ} \mathrm{C}, 2.16 \mathrm{~kg}\right)=1.0 ;$ density $=0.93 \mathrm{~g} /$ $\left.\mathrm{cm}^{3}\right]$.

\section{Preparation of Multilayer Films}

Prior to processing, PA-6 was dried in a vacuum oven for a period of $12 \mathrm{~h}$ at $90{ }^{\circ} \mathrm{C}$. PA-6, LDPE, and LDPE- $g$-MAH were coextruded through a three-layer coextrusion blown-film die (inner diameter $=97.6$ $\mathrm{mm}$; gap thickness $=1.2 \mathrm{~mm}$ ) at $250{ }^{\circ} \mathrm{C}$. Above the exit of the die, the three-layer film was inflated and cooled with air and stretched by a take-up device. Monolayers of PA-6 and LDPE films were also fabricated using the same blown-film apparatus. Before measuring their permeability and tensile behavior, all samples were placed for $14 \mathrm{~d}$ in cabinet maintained at $25{ }^{\circ} \mathrm{C}$ with a relative humidity of $50 \%$. The overall thickness of three-layer multilayered films was $c a$. $200 \mu \mathrm{m}$. Because the tie layer generally was very thin (ca. $5 \mu \mathrm{m}$ in this study) during the coextrusion process, and the main molecular structure was LDPE, we consider the tie layer to be part of the LDPE layer and neglect its effect on permeability and tensile behavior. Table I presents the thicknesses and volume

Table I. Thickness and volume fraction of PA-6 layer in three-layer films

\begin{tabular}{cc}
\hline $\begin{array}{c}\text { Thickness of PA-6 layer } \\
(\mu \mathrm{m})\end{array}$ & $\begin{array}{c}\text { Volume fraction of PA-6 layer } \\
(\%)\end{array}$ \\
\hline 20 & 10 \\
40 & 20 \\
60 & 30 \\
80 & 40 \\
100 & 50 \\
\hline
\end{tabular}

fractions of the PA-6 layers; we controlled these compositions using gear pumps.

\section{Measuring Gas Permeability}

The gas permeability, including that toward oxygen $\left(\mathrm{O}_{2}\right)$, nitrogen $\left(\mathrm{N}_{2}\right)$, and carbon dioxide $\left(\mathrm{CO}_{2}\right)$, was measured using a Lyssy L-100-5000 Gas Permeability Tester, ${ }^{24}$ following the ASTM Standard Method D1434. The gas permeability of the samples was measured at $23^{\circ} \mathrm{C}$ and at a relative humidity of $0 \%$. The temperature was controlled by a water bath. Measurements were taken on 5 replicate samples; average values are reported.

\section{Measuring Water Vapor Permeability}

Water vapor permeability was measured using a Lyssy L-80-5000 Water Vapor Permeability Tester, ${ }^{25}$ following the ASTM Standard Method E96. The permeability of the samples was measured at $38^{\circ} \mathrm{C}$ and at a relative humidity of $90 \%$. The temperature was controlled by a water bath. Measurements were taken using 5 replicate samples; average values are reported.

\section{Measuring Tensile Behavior}

We conducted uniaxial tensile measurements using a Hung-Ta Instrument 2102AP with test samples that were $20 \mathrm{~mm}$ wide and $20 \mathrm{~mm}$ long. Samples were tested with a crosshead speed of $20 \mathrm{~mm} / \mathrm{min}$ at a temperature of $25^{\circ} \mathrm{C}$ and a relative humidity of $50 \%$. Engineering stress-strain curves were determined from load-extension data based on the geometry of the initial specimen. Measurements were taken on 5 replicate samples; average values are reported.

\section{RESULTS AND DISCUSSION}

\section{Permeability}

The gas permeabilities of PA- 6 and LDPE films, including those toward $\mathrm{O}_{2}, \mathrm{~N}_{2}$, and $\mathrm{CO}_{2}$ as shown in Figures $1-3$. We see that the PA-6 film has much better barrier properties than LDPE toward all these gases, with permeabilities for both films increasing in the order $\mathrm{CO}_{2}>\mathrm{N}_{2}>\mathrm{O}_{2}$. In these figures, the gas permeabilities of three-layer films as a function of the volume fraction of the PA- 6 layer. The values of gas permeabilities all lie between those of the individual component layers for all the gases. As expected, the permeability toward all gases decreased upon increasing the volume fraction of the PA-6 layer. Because of the lamellar structure of the three-layer films, we applied a series model to predict the gas permeability of a three-layer film from that of its individual component layers: ${ }^{22}$ 


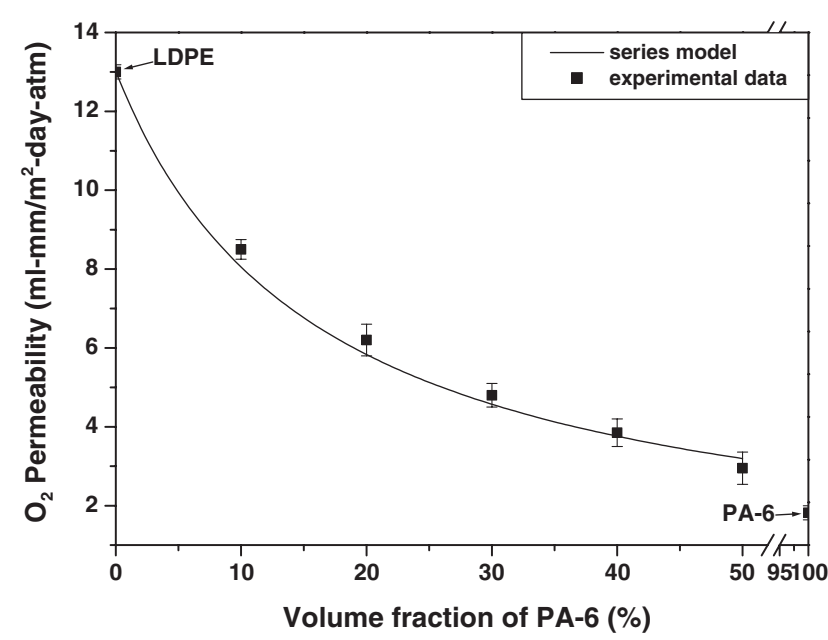

Figure 1. Oxygen $\left(\mathrm{O}_{2}\right)$ permeabilities of three-layer films as a function of volume fraction of PA-6 layer.

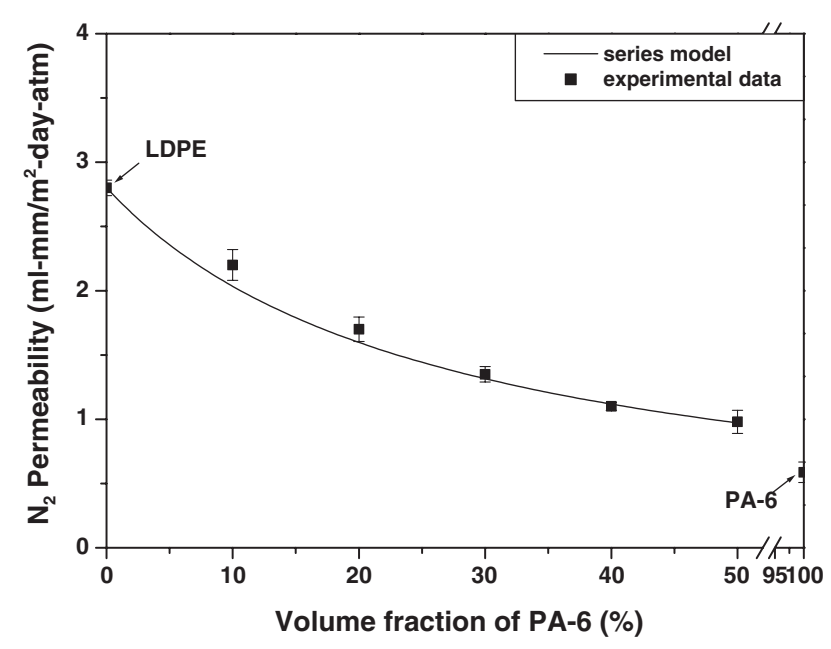

Figure 2. Nitrogen $\left(\mathrm{N}_{2}\right)$ permeabilities of three-layer films as a function of volume fraction of PA-6 layer.

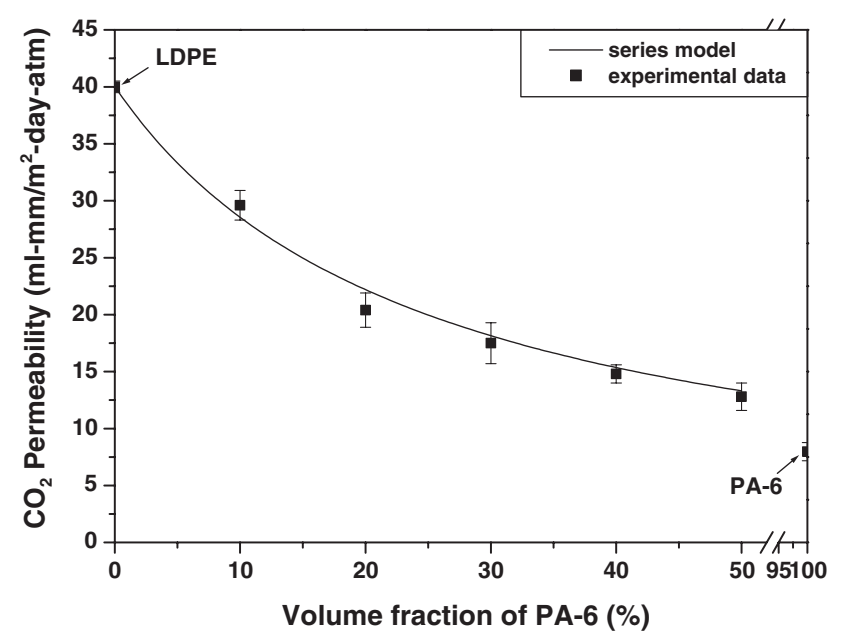

Figure 3. Carbon dioxide $\left(\mathrm{CO}_{2}\right)$ permeabilities of three-layer films as a function of volume fraction of PA-6 layer.



Figure 4. Water vapor permeabilities of three-layer films as a function of volume fraction of PA-6 layer.

$$
\frac{1}{P_{\mathrm{M}}}=\frac{\alpha_{\mathrm{PA}-6}}{P_{\mathrm{PA}-6}}+\frac{\alpha_{\mathrm{LDPE}}}{P_{\mathrm{LDPE}}}
$$

where $P_{\mathrm{M}}$ is the permeability of the three-layer film, $P_{\mathrm{PA}-6}$ and $P_{\mathrm{LDPE}}$ are the permeabilities of the monolayer films of PA-6 and LDPE, respectively, and $\alpha_{\mathrm{PA}-6}$ and $\alpha_{\mathrm{LDPE}}$ are the volume fractions of PA-6 and LDPE (including the tie layer) in the three-layer film, respectively. Figures 1-3 also show the gas permeabilities of three-layer films toward $\mathrm{O}_{2}, \mathrm{~N}_{2}$, and $\mathrm{CO}_{2}$, respectively, for the series model. We can see that a good agreement exists between the experimental data and the model's predictions for all these gases.

Figure 4 shows the water vapor permeabilities of PA-6 and LDPE films. In contrast to their gas barrier properties, we see that the LDPE film has enhanced water vapor barrier properties relative to those of the PA-6 film. The figure also presents the water vapor permeabilities of the three-layer films as a function of the volume fraction of the PA-6 layer. Similarly to the gas permeabilities, the values of water vapor permeabilities all lie between those of the individual component layers. For the sake of comparison, this figure also presents the predictions made by the model using $\mathrm{Eq} 1$. The water vapor permeabilities increase upon increasing the PA- 6 content and agree reasonably well with the series model.

\section{Tensile Behavior}

Figure 5 displays the engineering stress-strain curves for the monolayer films of PA-6 and LDPE. We see that the PA-6 film exhibits a ductile mechanical behavior. Upon initial deformation of the film sample, the engineering stress increases steadily with the engineering strain. As the engineering strain increases, the engineering stress almost remains constant and a so-called cold drawing takes place before 


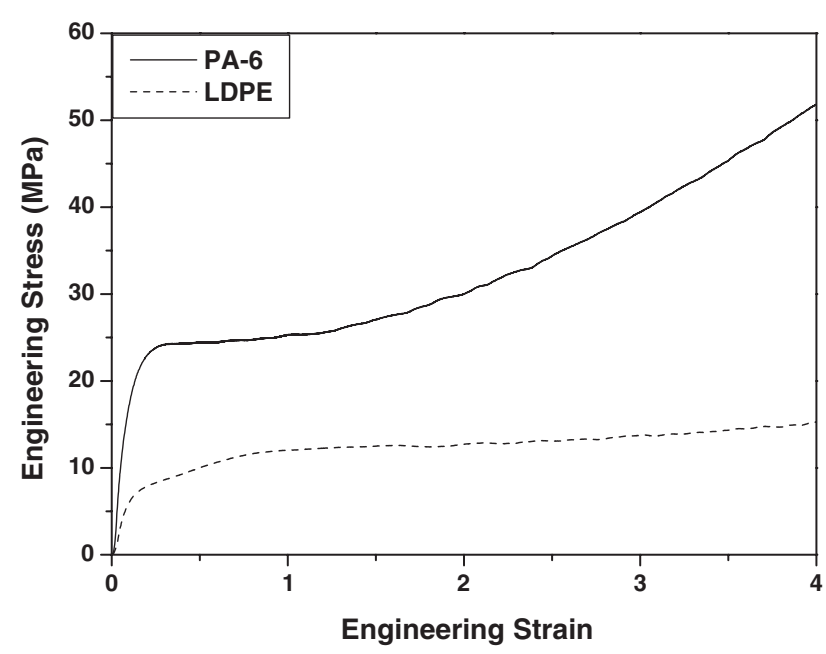

Figure 5. Engineering stress-strain curves of PA-6 and LDPE films.

the engineering strain becomes 1 . After the value of strain, the engineering stress increases with the increase of engineering strain due to the molecular alignment; ${ }^{26}$ this effect is known as strain hardening. On the other hand, the LDPE film exhibits a lower level of engineering stress and deforms in a manner that is characteristic of a rubbery material by its continuous increase of engineering stress with increasing strain.

We calculated the engineering stress and strain by considering the original geometry of the sample films, but, in fact, the cross-sectional area of a film sample changed continuously during deformation. The engineering stress and strain cannot represent the actual stress and strain at any one instance. It is necessary and more instructive to plot the true stress-strain curves to describe the tensile behavior. Because the deformation behavior of both the PA-6 and LDPE films were homogeneous, as presented in Figure 5, and a constant volume was assumed during deformation, the true strain, $\varepsilon_{\mathrm{T}}$, and the true stress, $\sigma_{\mathrm{T}}$, were calculated by

$$
\begin{aligned}
& \varepsilon_{\mathrm{T}}=\ln \left(1+\varepsilon_{\mathrm{E}}\right) \\
& \sigma_{\mathrm{T}}=\sigma_{\mathrm{E}}\left(1+\varepsilon_{\mathrm{E}}\right)
\end{aligned}
$$

where $\varepsilon_{\mathrm{E}}$ and $\sigma_{\mathrm{E}}$ are the engineering strain and the engineering stress, respectively. ${ }^{17,27}$ Figure 6 displays the true stress-strain curves of the PA- 6 and LDPE films as calculated using Eqs 2 and 3.

To model the deformation behavior of film, we introduced the following empirical constitutive equation: ${ }^{17,28}$

$$
\sigma=\sigma_{0} \exp \left(\gamma \cdot \varepsilon_{\mathrm{T}}\right)
$$

where $\sigma_{0}$ and $\gamma$ are the true yield stress and the strain hardening parameter, respectively. The constitutive equation can also be presented in the following form:

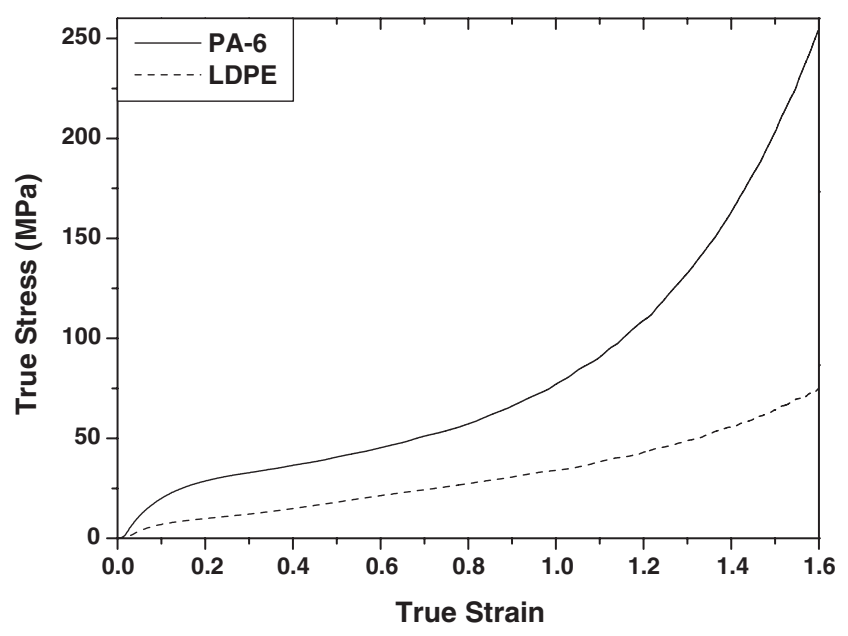

Figure 6. True stress-strain curves of PA-6 and LDPE films.

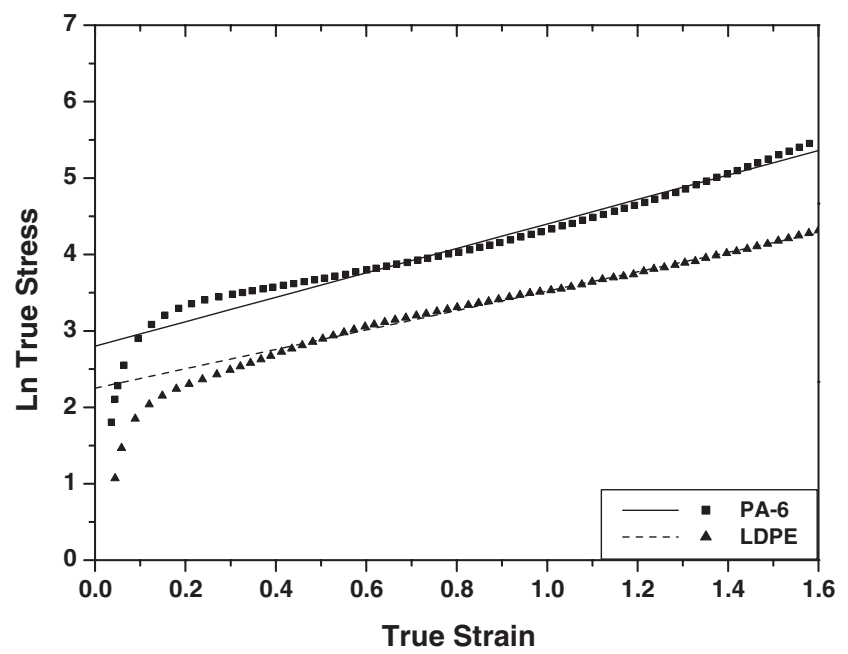

Figure 7. Modeling of Ln true stress-strain of PA-6 and LDPE films.

$$
\ln \sigma=\ln \sigma_{0}+\gamma \cdot \varepsilon_{\mathrm{T}}
$$

The plot of the natural logarithm of true stress $(\ln \sigma)$ $v s$. true strain $\left(\varepsilon_{\mathrm{T}}\right)$ should be linear in the region of plastic deformation. The intercept and slope of the least-squares approximation correspond to the natural logarithm of the true yield stress $\left(\ln \sigma_{0}\right)$ and the strain hardening parameter $(\gamma)$, respectively. Figure 7 presents the experimental data and fitted curves of the natural logarithm of the true stress versus true strain for the PA-6 and LDPE films. A linear relationship appears to exist over the range of true strains from 0.3 to 1.6 where correlation coefficients are all $>0.98$ with respect to the approximation. The parameters of the constitutive equation for the PA-6 and LDPE films are summarized in Table II. Figure 8 displays a comparison of the experimental true stress-strain data and the modeling curves. A good correlation exists between the experimental data and the modeling curves for the plastic deformation of the PA-6 and 
Table II. True yield stress $\left(\sigma_{0}\right)$ and strain hardening parameter $(\gamma)$ of LDPE, PA-6 and three-layer films

\begin{tabular}{crc}
\hline $\begin{array}{c}\text { Volume fraction of PA-6 layer } \\
(\%)\end{array}$ & $\begin{array}{c}\sigma_{0} \\
(\mathrm{MPa})\end{array}$ & $\gamma$ \\
\hline 0 (LDPE) & 9.49 & 1.27 \\
10 & 10.05 & 1.31 \\
20 & 10.66 & 1.41 \\
30 & 11.72 & 1.42 \\
40 & 12.00 & 1.48 \\
50 & 12.61 & 1.51 \\
100 (PA-6) & 16.44 & 1.60 \\
\hline
\end{tabular}



Figure 8. Comparison of true stress-strain curves between modeling curves and experimental data of PA-6 and LDPE films.

LDPE films. It is obvious that the model is only appropriate within the plastic deformation range.

Figure 9 presents a plot of the engineering and true stress-strain curves of three-layer films with respect to various compositions of PA-6. It is clear that these curves lie between those obtained for monolayers of PA-6 and LDPE. The stress level increases upon increasing the volume fraction of the PA- 6 layer and, in addition, the strain hardening behavior becomes more obvious. In the range of volume fractions of PA-6 that we investigated, all the three-layer films deform homogeneously. As Figure 11 indicates, a linear relationship also appears to exist for the three-layer films over the same range of true strains $(0.3-1.6)$ as it did for the PA-6 and LDPE films. The correlation coefficients are also all $>0.98$ with respect to the approximation. The corresponding parameters of the constitutive equation for the three-layer films with various volume fraction of PA-6 are presented in Table II. The values of these parameters, including the true yield stress and strain hardening parameters, also lie between those of the individual component layers. Figure 11 displays a comparison of the experimental true stress-strain data and the modeling curves. A good correlation also exists between the ex-

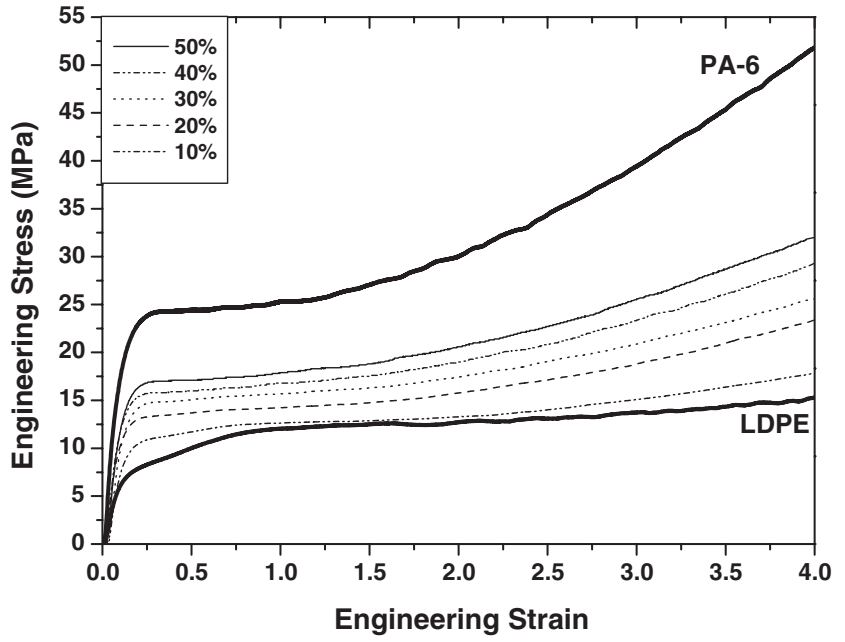

(a)

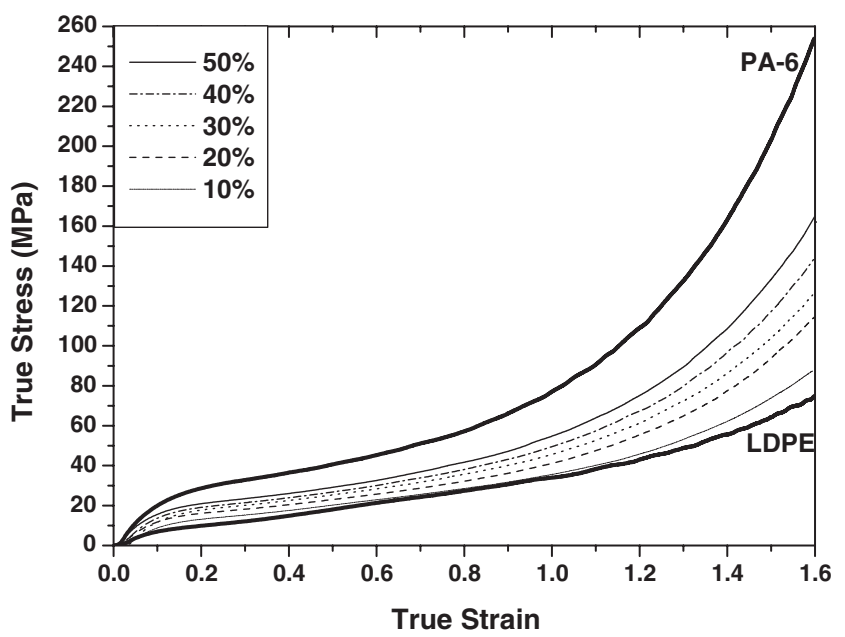

(b)

Figure 9. Stress-strain curves of three-layer films as a function of volume fraction of PA-6 layer. Thick solid lines represent the component layer of PA-6 and LDPE, respectively. (a) Engineering; (b) True.

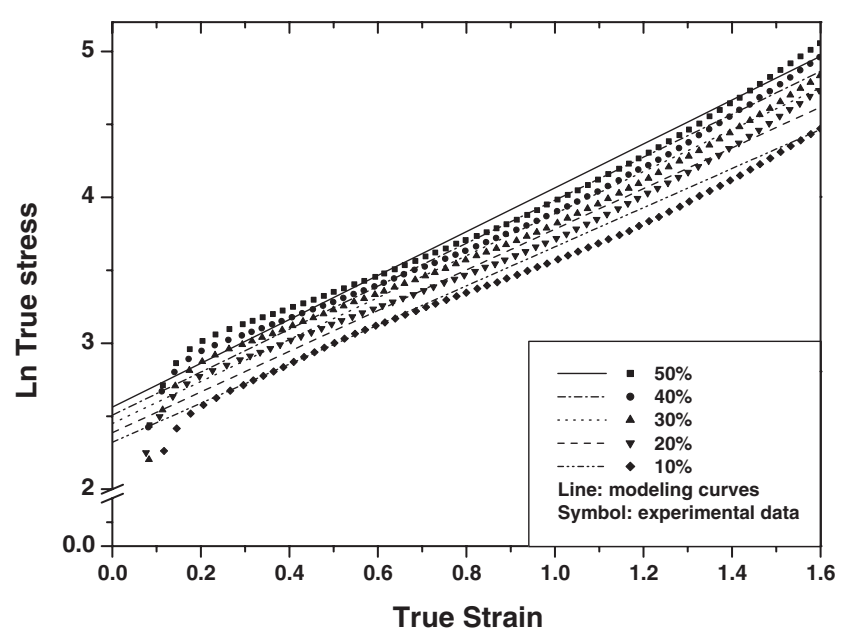

Figure 10. Modeling of Ln true stress-strain of three-layer films as a function of volume fraction of PA-6 layer. 




Figure 11. Comparison of true stress-strain curves between modeling curves and experimental data of three-layer films as a function of volume fraction of PA-6 layer.

perimental data and the modeling curves for the plastic deformation of the three-layer films having various volume fractions of PA-6.

Similar to what we reported above for predicting permeability, we used a simple theoretical additive rule model $^{23}$ to predict the tensile behavior of a three-layer film from those of its individual component layers:

$$
\sigma_{\mathrm{M}}=\alpha_{\mathrm{PA}-6} \sigma_{\mathrm{PA}-6}+\alpha_{\mathrm{LDPE}} \sigma_{\mathrm{LDPE}}
$$

where $\sigma_{\mathrm{M}}$ is the true stress of a three-layer film, $\sigma_{\mathrm{PA}-6}$ and $\sigma_{\mathrm{LDPE}}$ are the true stresses of the PA- 6 and LDPE layers, respectively, and $\alpha_{\mathrm{PA}-6}$ and $\alpha_{\mathrm{LDPE}}$ are the volume fractions of PA- 6 and LDPE (including the tie layer) layers, respectively.

From Eqs 4 and 6, the relationship between the true stress-strain of the three-layer and individual component layer films is:

$$
\begin{aligned}
\sigma_{0 \mathrm{M}} \exp \left(\gamma_{\mathrm{M}} \cdot \varepsilon_{\mathrm{T}}\right)= & \alpha_{\mathrm{PA}-6} \sigma_{0 \mathrm{PA}-6} \exp \left(\gamma_{\mathrm{PA}-6} \cdot \varepsilon_{\mathrm{T}}\right) \\
& +\alpha_{\mathrm{LDPE}} \sigma_{0 \mathrm{LDPE}} \exp \left(\gamma_{\mathrm{LDPE}} \cdot \varepsilon_{\mathrm{T}}\right)
\end{aligned}
$$

where $\sigma_{0 \mathrm{M}}$ is the true yield stress of the three-layer film, $\sigma_{0 \mathrm{PA}-6}$ and $\sigma_{0 \mathrm{LDPE}}$ are the true yield stresses of the PA-6 and LDPE layers, respectively, and $\gamma_{\mathrm{M}}$, $\gamma_{\mathrm{PA}-6}$, and $\gamma_{\mathrm{LDPE}}$ are the strain hardening parameters of the three-layer film, PA-6, and LDPE layers, respectively. It is reasonable to believe that the true yield stress of the three-layer film alone follows the additive rule:

$$
\sigma_{0 \mathrm{M}}=\alpha_{\mathrm{PA}-6} \sigma_{0 \mathrm{PA}-6}+\alpha_{\mathrm{LDPE}} \sigma_{0 \mathrm{LDPE}}
$$

and the strain hardening parameter of the three-layer film is defined as: ${ }^{29}$

$$
\begin{aligned}
\gamma_{\mathrm{M}}(\varepsilon) & =\frac{\partial \ln \sigma_{\mathrm{M}}}{\partial \varepsilon} \\
& =\frac{\partial\left[\alpha_{\mathrm{PA}-6} \sigma_{0 \mathrm{PA}-6} \exp \left(\gamma_{\mathrm{PA}-6} \cdot \varepsilon\right)+\alpha_{\mathrm{LDPE}} \sigma_{0 \mathrm{LDPE}} \exp \left(\gamma_{\mathrm{LDPE}} \cdot \varepsilon\right)\right]}{\partial \varepsilon}
\end{aligned}
$$

We calculated the parameters $\sigma_{0 \mathrm{M}}$ and $\gamma_{\mathrm{M}}$ for the additive rule by using the parameters of the individual component layers in Table II. Figure 12 presents the dependence of these parameters obtained by additive rule and the experimental data (from Table II) with respect to the films' compositions. The good agreement existing between the experimental data and the additive-rule model suggests that this rule can be used to accurately predict the plastic deformation of the three-layer films.

As we mentioned above, the constitutive equation is only valid in large-strain plastic deformation. In small-strain deformation, modulus is the most important mechanical property. Thus, we also examined the validity of the additive rule with respect to the modulus. Table III lists the tensile modulus of the individual component layers of PA-6 and LDPE. We see that the PA-6 film performance is stiffer and more rigid than that of LDPE. The tensile moduli of three-layer films are also presented in Table III. The tensile modulus increases upon increasing the PA-6 content. The
Table III. Tensile moduli of LDPE, PA-6 and three-layer films

\begin{tabular}{cc}
\hline $\begin{array}{c}\text { Volume fraction of PA-6 } \\
(\%)\end{array}$ & $\begin{array}{c}\text { Tensile modulus } \\
(\mathrm{MPa})\end{array}$ \\
\hline $0(\mathrm{LDPE})$ & 111.52 \\
10 & 129.04 \\
20 & 154.08 \\
30 & 162.03 \\
40 & 194.57 \\
50 & 209.56 \\
100 (PA-6) & 297.21 \\
\hline
\end{tabular}

model of the additive rule can be stated as follows:

$$
M_{\mathrm{M}}=\alpha_{\mathrm{PA}-6} M_{\mathrm{PA}-6}+\alpha_{\mathrm{LDPE}} M_{\mathrm{LDPE}}
$$

where $M_{\mathrm{M}}$ is the tensile modulus of the three-layer film, and $M_{\mathrm{PA}-6}$ and $M_{\mathrm{LDPE}}$ are the tensile moduli of the PA-6 and LDPE layers, respectively. Figure 13 provides a comparison between the moduli obtained by the additive rule and the experimental data (from 


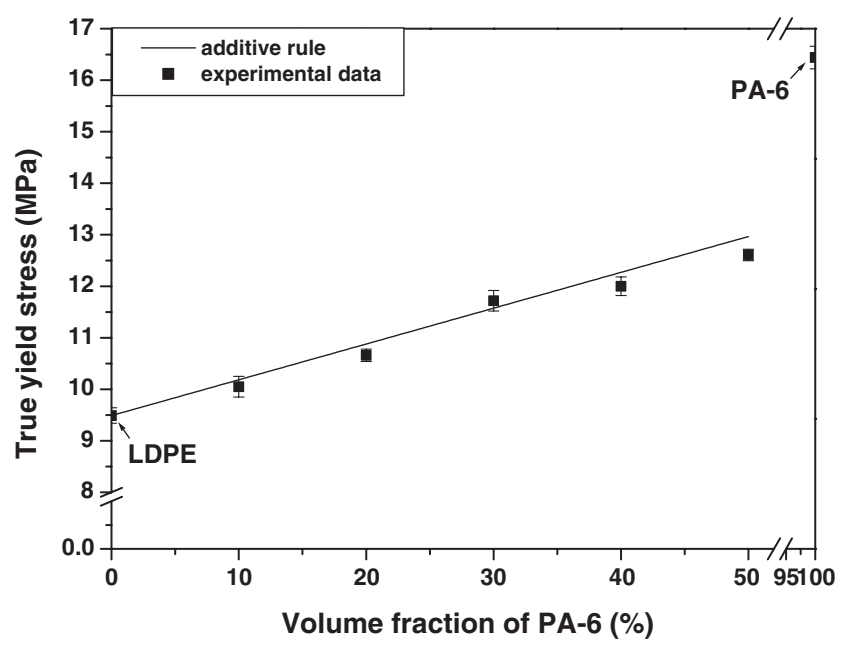

(a)

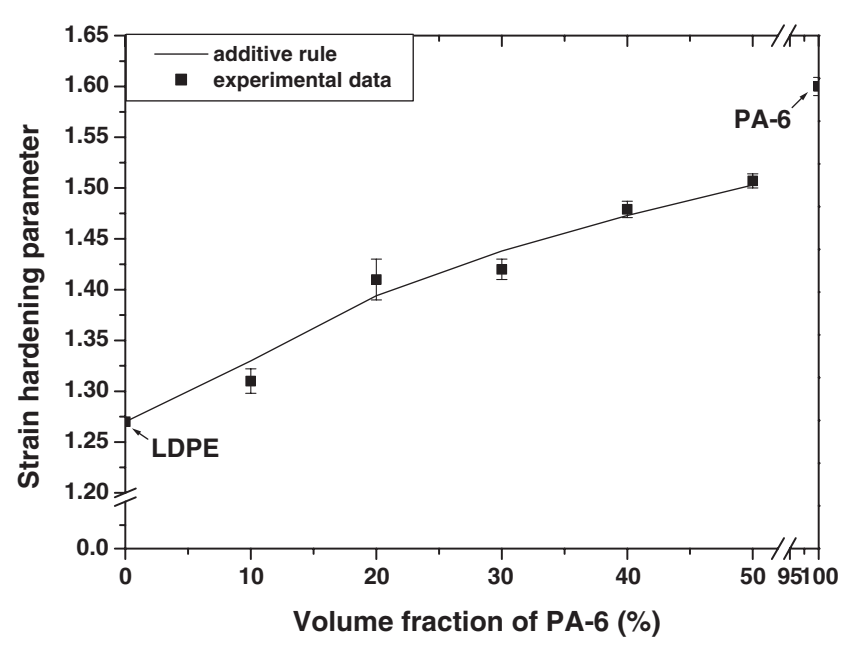

(b)

Figure 12. Comparison of mechanical parameter between additive rule and experimental data as a function of PA- 6 content. (a) The true yield stress; (b) the strain hardening parameter.

Table III). A good agreement also exists between these systems with regard to their tensile moduli.

\section{CONCLUSIONS}

We have successfully fabricated three-layer films, which are typical multilayer structure A/B/C films, by a coextruded blown-film process. We have investigated the permeabilities, including those toward three gases and water vapor, and tensile behaviors of monolayers of PA-6 and LDPE and their multilayer films. We examined the relationships between the properties of the monolayers of the component materials and those of the three-layer films by predictions using a series model and an additive rule to obtain the permeabilities and tensile behaviors, respectively. We found that predicting the gas permeability, with respect to $\mathrm{O}_{2}, \mathrm{~N}_{2}$, and $\mathrm{CO}_{2}$, of the three-layer films based upon those of the individual component layer films occurs

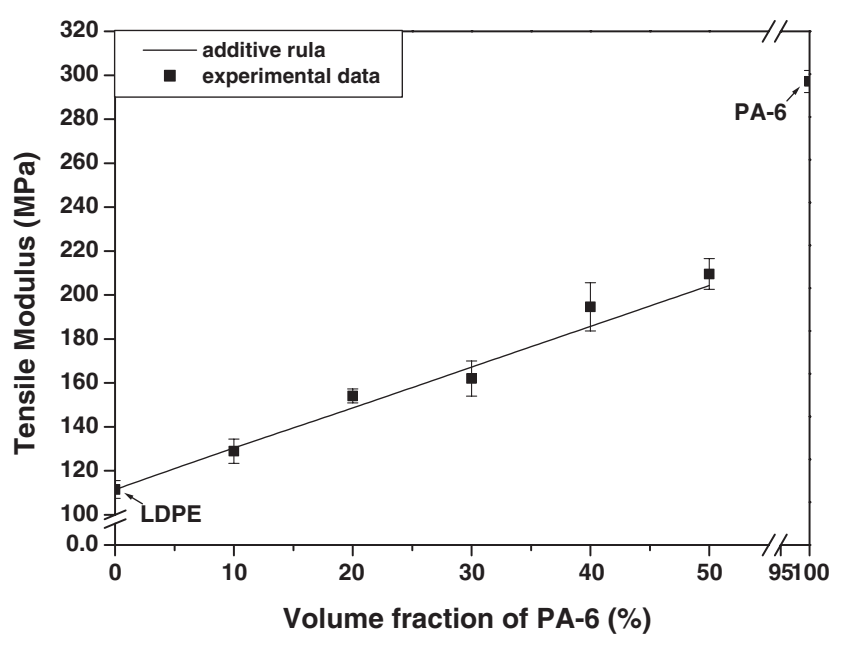

Figure 13. Comparison of tensile modulus between additive rule and experimental data as a function of PA- 6 content.

in good agreement with the experimental data when using the series model. This model is also useful for predicting the water vapor permeability with respect to the volume fraction of PA-6. The tensile behavior of the component-layer and multilayer films can be expressed by a constitutive equation having two parameters in the true stress-strain relationship, i.e., the true yield stress and the strain hardening parameter. We can also predict the tensile properties-including the true yield stress, strain hardening, and tensile modulus - of the three-layer film from those of the individual component layers with good agreements in the true stress-strain relationship by using the additive rule.

As mentioned above, these model predictions provide an economical and efficient tool for designing multilayer structures, formed by a coextrusion process, that possess specific permeability and/or tensile properties.

\section{REFERENCES}

1. J. K. Rogers, Mod. Plast., 67, 46 (1990).

2. S. Hosoda, Y. Seki, and H. Kihara, Polymer, 34, 4602 (1993).

3. J. Culter, J. Krohn, and W. Todd, Packag. Tech. Eng., 8, 30 (1999).

4. S. J. Liu and C. H. Yang, Adv. Polym. Technol., 20, 108 (2001).

5. G. L. Wooddell, Tappi Notes, 1986, 21.

6. M. S. Pucci and R. N. Shroff, Polym. Eng. Sci., 26, 569 (1986).

7. J. F. Graham, M. Predrag, and N. B. Sati, Polym. Int., 48, 461 (1999).

8. S. A. Jabarin and W. J. Kollen, Polym. Eng. Sci., 25, 1156 (1988).

9. P. M. Subramanian, Polym. Prepr., 30, 28 (1989).

10. D. C. Climenhage, Packaging, 32, 39 (1987). 
11. S. Eichler and J. Miltz, J. Appl. Polym. Sci., 50, 2095 (1993).

12. Y. P. Khanna, E. D. Day, M. L. Tsai, and G. Vaidyanathan, J. Plast. Film Sheet., 13, 197 (1997).

13. M. Eldridge, J. Wanger, and R. John, J. Plast. Film Sheet., 17, 221 (2001).

14. H. Tanaka, H. Shigemoto, and H. Kawchi, J. Plast. Film Sheet., 12, 279 (1996).

15. M. G. Botros, J. Plast. Film Sheet., 12, 195 (1996).

16. G. W. Kamykowski, J. Plast. Film Sheet., 16, 237 (2000).

17. S. Bahadur, Polym. Eng. Sci., 13, 266 (1973).

18. Y. Wang, A. J. Easteal, and X. D. Chen, Packag. Tech. Sci., 11, 169 (1998).

19. S. Y. Lee and S. C. Kim, Polym. Eng. Sci., 37, 463 (1997).

20. S. Bianchi, S. Cantagallo, G. Consolati, M. Laporta, M. Pegoraro, G. Tieghi, and L. Zanderighi, J. Appl. Polym. Sci., 86, 559 (2002).
21. G. F. Akbar, J. Plast. Film Sheet., 15, 194 (1999).

22. J. B. Faisant, A. Aït-Kadi, M. Bousmina, and L. Deschênes, Polymer, 39, 533 (1998).

23. W. J. Schrenk and T. Alfrey, Polym. Eng. Sci., 9, 393 (1969).

24. Automatic Manometric Gas Permeability Tester Operator Manual, Model L100-5000, Lyssy AG (2001).

25. Automatic Manometric Water Vapor Permeability Tester Operator Manual, Model L80-5000, Lyssy AG (2001).

26. A. Peterlin, J. Mater. Sci, 6, 490 (1971).

27. M. Al-Hussein and G. Strobl, Macromolecules, 35, 8515 (2002).

28. V. Gaucher-Miri, G. K. Jones, R. Kaas, A. Hiltner, and E. Baer, J. Mater. Sci., 37, 2635 (2002).

29. E. W. Hart, Acta Metall., 15, 351 (1967). 